\title{
What Factors Direct the Customers' Intention of Purchasing Branded Apparel; An Investigation in the Western Province in Sri Lanka
}

\author{
W.G.T. Dimagi ${ }^{1} \&$ H.M.A. Herath ${ }^{2}$ \\ ${ }^{1,2}$ Department of Business Management \\ Faculty of Business Studies \& Finance \\ Wayamba University of Sri Lanka \\ Kuliyapitiya. \\ SRI LANKA \\ tharushadimagi@yahoo.com ${ }^{1}$, herathhma@wyb.ac.lk ${ }^{2}$
}

\begin{abstract}
More or less, the brand is a key factor in different industries. The concept of brand personality as a human related component of the brand is pivotal in making the consumer purchase intention favorable towards a particular brand of a product. In the recent past, it can be seen a greater tendency of people throughout the world for more concerning the green concept in industries due to the grown consciousness for environmental protection. This tendency is gradually being extended even towards customer behavior. This study tested a model which couples brand personality and eco consciousness of consumers as independent variables and consumer purchase intention as the dependent variable. The model was tested in the branded apparel industry, since the brand name is a critical success factor in this industry. The objectives of the study were to investigate the magnitude of effect of brand personality and eco consciousness on consumers' purchase intention of branded apparels. The model was tested among randomly selected sample of 200 apparel consumers in western province by using correlation and multiple regression analysis. It was based on a comprehensive literature review and the research was designed as a survey by collecting data from the sample using a standard questionnaire The results revealed that both brand personality and eco consciousness has significant positive impacts on consumer's purchase intention. The findings imply that the consumers have more concern whether the apparel manufactures comply with eco friendliness when they make their purchasing decisions. The effect of brand personality proves that it is also a significant factor in making consumers purchasing decision on branded apparels. However, when the findings are compared with previous studies in the world, obviously, the effect of two independent variables on purchasing intention remains lower than the consumers in other western countries. It gives a signal for Sri Lankan apparel manufactures for being proactive by preparing their manufacturing processes to comply with eco friendliness since this lower level of impact may become gradually stronger in line with global consumer behavior. Moreover, they should make stronger the brand personality component by targeting
\end{abstract}


the characteristics of their market segment/s into consideration. It is proposed for the future researchers to pay more attention specially on eco consciousness of Sri Lankan consumers since the significance of the effect of the variable on consumer purchasing behavior are to be reconfirmed.

Keywords: Brand personality, Eco consciousness, Apparel industry, Sri Lanka, consumer behaviour

\section{INTRODUCTION}

The consumer behavior in apparel industry has its own characteristics since the brand is a critical success factor. Specially, the branded apparel consumers can be considered as a separate segment due to their higher concern on the brand name when they are making purchasing decision (Gauzente and Roy 2012). In the consumer buying behavior process, just before engaging in purchasing action, the consumer makes an intention to purchase. unless any contingent factor prevents the action, most probably, they implement the intention. According to Laroche \& Zhol, (1996) purchase intention is defined as the individual's intention on buying a specific brand of product.

In the consumer segment of branded apparel, the brand name plays a critical role in influencing the consumer purchase behavior. The many previous studies have proven the influencing capacity of brand name in purchasing branded apparel by consumers. However, among the dimensions of brand name, the brand personality has rarely studied in the Sri Lankan context. Aaker (1997) defines brand personality as "a set of human characteristics associated to a brand." Hence, the functions of selfsymbolization and self-expression are offered to the customers by brand personality (Keller, 1993). The brand personality among other dimensions of a brand name is thus a factor that may highly influence consumer choice and preference (Biel, 1993). it has been investigated as a dimension that generates value for the consumer and the company (D. A. Aaker, 1991, 1996). Some of the previous studies have asserted that the consumers find it natural to build relationships with brands (Fournier, 1998) and to embed them with different personality characteristics, such as 'elegant' or 'confident' (Aaker, 1997; Plummer, 2000).

Some other studies have found that the brand personality dimension is an important component for creating a brand differentiation which may directly affect the Consumer's purchase decision (Aaker, 1997). As per Wang and Yang, (2008), stronger the brand personality is, the higher the consumers' purchase intention toward the branded products.

The brand personality largely contributes to create the brand image that have already been positioned consumers' minds rather than positioning the original attributes or the characteristics of the product itself (Dick et al., 1990).

In recent past, the people at the global level had a more concern on eco friendliness with the spread of the green concept. Some of the studies in 
western countries has considered how far consumers are conscious on eco system and how that concern affects their purchasing behavior. It has been conceptualized as eco- consciousness of consumers. The eco-consciousness refers to the psychological factors that determine individuals' propensity towards pro environmental behaviors (Zelezny and Schultz,2000). Consumers are becoming sensitive to the extent of avoiding the purchasing of environmentally harmful products. Eco-consciousness is a multidimensional construct known to be influenced a person's knowledge, attitude, behavior, intentions and actions (Singh and Gupta, 2013; Dunlap et al., 2002; van Liere and Dunlap 1981).

As Lee et al. 2012 studied, the consumers' perception of eco-friendly apparel brands provides positive influences to their purchasing intention. Researches indicate that the involvement in eco-conscious apparel acquisition increases among consumers who understand how branded apparel products affect the environment (Hustvedt and Dickson,2009; Stephens, 1985). Also consumers' purchase intention directly influences the green branded apparel products, since such products are eco-friendly, safe, and good for their health (Lai and Cheng 2016).

Some studies have shown that the consumers who are more likely to practice eco-friendly behavior tend to purchase more green branded apparel products (Diamantopoulos et al., 2003; Zimmer et al., 1994).

\subsection{The issue in the Sri Lankan context}

The Sri Lankan consumers have the freedom to choose the local brands of apparel and the market remains very competitive. The common Sri Lankan consumers are price sensitive and therefore, the price will influence their buying decisions Jayasingh and Eze 2012). However, the behavior of the branded apparel consumer segment may be different from the common consumers since they are mostly coming from the up market and likely to be brand and quality conscious. Nevertheless, in this segment, the studies related to consumer purchasing behavior is lacking. No studies have been conducted specially for investigating eco consciousness of consumers in this segment in Sri Lankan apparel industry. Since it is the branded apparel consumer segment, the brand may play a pivotal role in consumer purchasing decision. Though there are few studies on the brand, brand loyalty and brand image, the brand personality has very rarely been studied. Therefore, a research model with eco consciousness and brand loyalty as predictor variables may be a parsimonious but strong model in this segment.

\subsection{The research Model}

Growth of the number of branded apparels clearly widened the consumer choices in terms of purchasing because consumers have a variety of brand positions in their mind when they go to buy clothes and the consumer will ultimately decide which apparel brand should purchase. Therefore, how the brands positioned 
in the mind of the consumer has been a decisive factor to attract more customers. As a result, it is interesting to identify which factors are influencing Sri Lankan consumer choice to buy branded apparel.

Based on the premise discussed in the literature on brand personality and eco-consciousness and the features of the segment in Sri Lankan context, the study conceptualized the research model as shown in Figure 1.

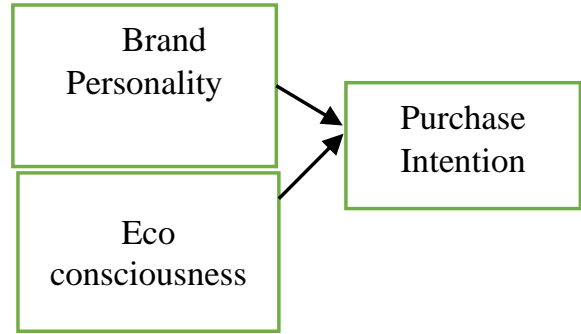

Figure 1. Research Model

Based on the conceptual model, the following questions were answered by testing the model in Sri Lankan context.

\subsection{Research Questions}

- What is the level purchase intention of branded apparels among consumers in the Western Province?

- What is the relationship between brand personality and purchase intention?

- What is the relationship between eco consciousness and purchase intention?

- To what extent does each factor (brand personality and eco consciousness) affects the purchase intention?
For answering the specified research questions by testing the proposed research model, four specific objectives were formulated as given below.

\subsection{Research Objectives}

- To identify the level of purchase intention of branded apparels among consumers in the Western Province.

- To investigate the relationship between brand personality and purchase intention of consumers in Western Province

- To investigate the relationship between eco consciousness and purchase intention of consumers in Western Province

- To explain the impact of brand personality \& eco-consciousness on consumers' purchase intention

\subsection{Hypotheses}

For calculating the statistical values for the two direct paths of the theoretical framework to find the model fit to the real context, the study formulated two hypotheses to prove the relationships and the impacts of the predictor variables and the criterion variable.

H1: There is a positive relationship between Brand Personality and Purchase Intention and brand personality significantly affect the purchase intention.

H2: There is a positive relationship between eco consciousness and purchase intention and eco consciousness significantly affect the purchase intention. 


\section{METHODS}

\subsection{Research Design}

The current research aims to examine the impact of brand personality \& ecoconsciousness towards the consumers' purchase intention. Accordingly, the positivistic method is suited while deductive reasoning was the approach. The time horizon of the study was cross sectional and study setting was non-contrive and unit of analysis was individual customers.

\subsection{Population and Sample}

The target population of this present work is the consumers in Western Province who purchase the branded apparels. The survey sampling frame couldn't be defined since there were no source of exact number of consumers. The sample size consisted of 200 respondents whom were selected as per the Morgan table.

\subsection{Measures, Data Collection and Analysis}

Survey questionnaire was used to collect data for the purpose of this study. In order to collect primary data, a self-administered questionnaire was used, and it requires respondents to answer. the questions in a decided order (de Vaus 2002). The questionnaire was posed to the sample members by using Google Forms. The structured measurements were used to operationalize the variables and they were adapted for the current study.

Thus, having collected the completed questionnaires from the online survey, the data were analyzed by using the correlation and multiple regression analysis for testing the hypotheses.
The descriptive analysis was performed to identify the univariate behavior of variables and to analyze the sample characteristics.

\subsection{Testing Multivariate Assumptions}

Before performing the mainstream data analysis for hypotheses testing, multivariate assumptions were tested to check the suitability of variables for multiple regression analysis.

\subsection{Normality}

When testing for normality, it was mainly checked by using the Normal Q-Q Plots. The graphical representation of the plots indicates that the data appears to be normally distributed as it follows the diagonal line closely and does not appear to have a non-linear pattern.

As the figure 2. indicates, the independent variable brand personality has no deviation from the normal distribution and suitable for using in the multiple regression model.

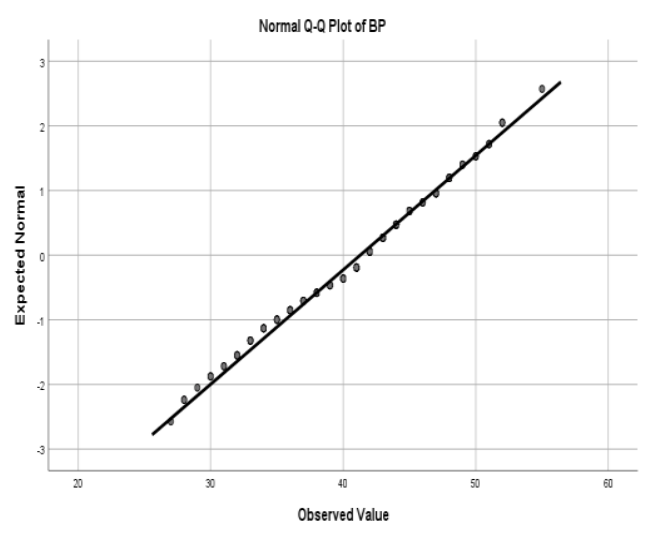

Figure 2. Q Q Plots for Brand Personality 


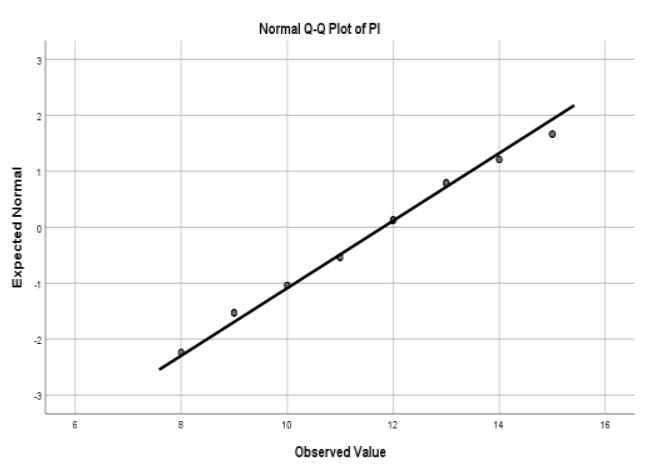

Figure 3. Normal distribution of Purchase Intention

Also, the figures 3 and 4. show the variables purchase intention and eco consciousness are respectively normally distributed proving their suitability for using in the regression model.

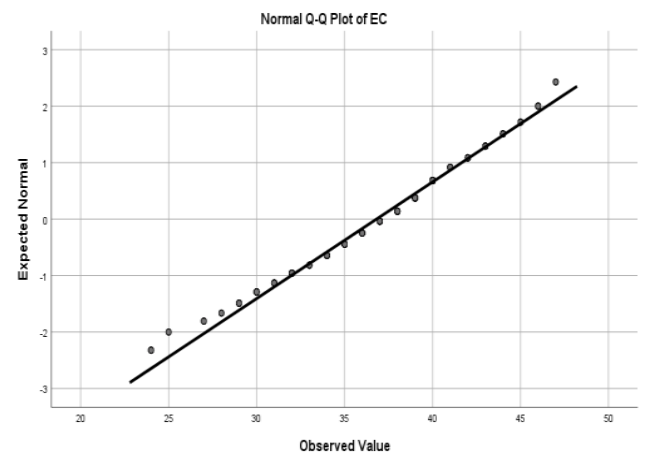

Figure 4. Normal distribution of Eco Consciousness

\subsection{Linearity}

Linearity of variables was assessed by the examining the scatter plots. The graphical representation of the scatter plots for all variables indicates a good linear relationship, which allows to conduct a linear regression analysis. (figure 5.)

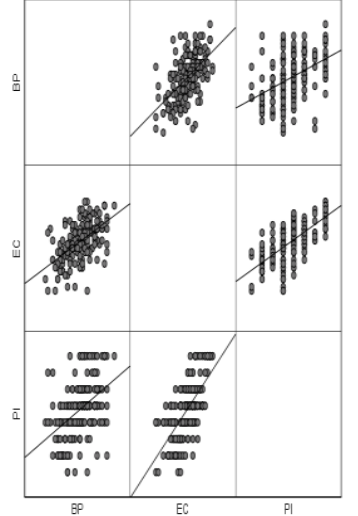

Figure 5. Linearity of the variables

\subsection{Auto correlation}

The auto correlations among variables were tested by estimating the DurbinWatson value. The value is according to the table 1 . is 1.864 and approximates 2. Therefore, it can be concluded that there is no auto correlation.

\subsection{Multicollinearity}

To test the assumption of multicollinearity, VIF and tolerance indices were used, the values are given in the table 2.

Table 2. Multicollinearity statistics, VIF and Tolerance values

\begin{tabular}{|c|c|c|c|c|c|c|c|c|}
\hline & & & & efficients $^{a}$ & & & & \\
\hline & & Unstandardiz & Coefficients & $\begin{array}{l}\text { Standardiced } \\
\text { Coefficientis }\end{array}$ & & & Collinearit & atistics \\
\hline Nodel & & B & sta. Error & Beta & $t$ & Sig. & Tolerance & VIF \\
\hline 1 & (Constant) & 2876 & .744 & & 3.867 & .000 & & \\
\hline & $B P$ & .026 & .019 & .088 & 1.378 & .170 & .663 & 1.464 \\
\hline & EC & .214 & .022 & .624 & 9.766 & .000 & .683 & 1.464 \\
\hline & endenttva & & & & & & & \\
\hline
\end{tabular}

As per the collinearity statistics, the VIF value of 1.464 , means that it lays between 1 to 10 , it can be concluded that there are no multicollinearity symptoms. 


\section{RESULTS}

\subsection{Descriptive statistics}

For understanding the beaviour patterns of single variables Descriptive statistics were estimated. Accordingly, minimum and maximum values, mean and standard deviation were observed. The results show in the table 3. Belo

\section{Table 3. Descriptive Statistics}

\begin{tabular}{|l|lllll|}
\hline \multicolumn{3}{|l|}{ Descriptive Statistics } & & & \\
& N & Minimum & Maximum & Mean & Std. Deviation \\
\hline BP & 200 & 27.00 & 55.00 & 41.2200 & 5.70652 \\
\hline EC & 200 & 24.00 & 47.00 & 36.8173 & 4.84316 \\
\hline PI & 200 & 8.00 & 15.00 & 11.8000 & 1.64729 \\
\hline Valid N (listwise) & 200 & & & & \\
\hline
\end{tabular}

In the table 3, it shows that the highest mean value reports by brand personality while next value represents by eco consciousness. The lowest mean value remains with purchase intention. The mean value of brand personality \& eco consciousness is higher than the mean value of purchase intention.

\subsection{Correlation Analysis}

The Pearson correlation coefficients among variables were estimated to investigate the bivariate relationships among independent and dependent variables. (Table 4) One of the objectives of this study is to evaluate the relationship between brand personality and purchase intention. This table shows Pearson's value of 0.439 was positive. The value represents a moderately strong correlation.

\section{Table 4. Pearson Correlation}

\begin{tabular}{|c|c|c|c|c|}
\hline \multicolumn{5}{|c|}{ Correlations } \\
\hline & & $\mathrm{PI}$ & $\mathrm{BP}$ & $\mathrm{EC}$ \\
\hline \multirow[t]{3}{*}{ PI } & Pearson Correlation & 1 & $.439^{* *}$ & $.674^{4}$ \\
\hline & Sig. (2-tailed) & & .000 & .000 \\
\hline & $\mathrm{N}$ & 200 & 200 & 200 \\
\hline \multirow[t]{3}{*}{$\mathrm{BP}$} & Pearson Correlation & $.439^{* 4}$ & 1 & $.563^{* 4}$ \\
\hline & Sig. (2-tailed) & .000 & & .000 \\
\hline & $\mathrm{N}$ & 200 & 200 & 200 \\
\hline \multirow[t]{3}{*}{$\mathrm{EC}$} & Pearson Correlation & $.674^{* 4}$ & $.563^{*+}$ & 1 \\
\hline & Sig. (2-tailed) & .000 & .000 & \\
\hline & $\mathrm{N}$ & 200 & 200 & 200 \\
\hline \multicolumn{5}{|c|}{ **. Correlation is significant at the 0.01 level (2-tailed). } \\
\hline
\end{tabular}

When the brand personality increases, the purchase intention also increases. As well as it shows significant value of 0.000 and can be concluded that there is a statistically significant correlation between brand personality $\&$ purchase intention.

The relationship between eco consciousness and purchase intention shows Pearson's value of 0.674 which was positive and there is a moderately strong correlation. when the eco consciousness increases, the purchase intention also increases. The significant value of 0.000 indicates that there is a statistically significant correlation between eco consciousness \& purchase intention. It means, increases or decreases in eco consciousness do significantly relate to increases or decreases in purchase intention.

\subsection{Regression analysis}

As per the results of regression analysis, the regression model estimated shows a good fit with the 
assumed model. It also indicates that the research mode tested exists in the real context of branded apparel industry.

\section{Table 5. The Regression Model}

\begin{tabular}{|c|c|c|c|c|c|c|}
\hline \multicolumn{7}{|c|}{ ANOVA: } \\
\hline \multicolumn{2}{|c|}{ Model } & \multirow{2}{*}{\begin{tabular}{|l} 
Sum \\
Squares \\
247.276
\end{tabular}} & \multirow{2}{*}{$\begin{array}{l}\text { Df } \\
2\end{array}$} & \multirow{2}{*}{\begin{tabular}{|l} 
Mean Square \\
123.638
\end{tabular}} & \multirow{2}{*}{$\begin{array}{l}F \\
82.314\end{array}$} & \multirow{2}{*}{$\frac{\text { Sig. }}{.000^{\mathrm{h}}}$} \\
\hline 1 & Regression & & & & & \\
\hline & Residual & 291.394 & 194 & 1.502 & & \\
\hline & Total & 538.670 & 196 & & & \\
\hline \multicolumn{7}{|c|}{ a. Dependent Variable: PI } \\
\hline \multicolumn{7}{|c|}{ b. Predictors: (Constant), EC, BP } \\
\hline
\end{tabular}

As the per the F statistic of the table 5 . and $\mathrm{P}$ value being less than .001, it proves a good model fit. Moreover, it indicates that brand personality and eco consciousness are good predictors of the dependent variable purchase intention. The $\beta$ values for both independent variables are also significant at the significant level .001 and therefore both brand personality and eco consciousness significantly affect the consumers' purchase intention on branded apparels.

Accordingly, as per the results of correlation and regression analysis two hypotheses formulated in this study can be accepted.

\section{CONCLUSION AND RECOMMENDATIONS}

This study aims were to investigate the brand personality \& eco consciousness and their relationships with and effect on purchase intention. The correlation analysis, and the regression analysis confirmed the significance of brand personality, eco consciousness in the consumers 'purchase intention of branded apparels

Empirical results confirmed the positive and statistically significant effect of brand personality on purchase intention. Therefore, it is possible, in this study, to draw the conclusion that brand personality has an effect on consumers' purchase intention. Eco consciousness is also positively correlating with consumers' purchase intention. Therefore, it is possible to draw the conclusion that eco consciousness has an effect on consumers' purchase intention.

The results of this study related to brand personality and purchase intention is consistent with previous studies, (eg. Son et al. 2013; Vikkraman and Sumathi 2012). Hence, it revealed that individual consumers desire to see their very own personal characteristics and identity in selecting apparel products. They wish to differentiate themselves from others in the society with a unique fashion sense. Also the results imply that branded apparel manufacturers have to make a major concern on the brand personality dimension of their brand. That dimension will be much helpful for strongly positioning a particular brand in the mind of branded apparel consumers. From the side of consumers, it seems that they are becoming more eco conscious and tis mind set will be a stronger predictor of branded apparel purchase intention. However, when the results are compared with similar studies of western, it can be observed that the impact of eco consciousness is not so stronger in the Sri Lankan context. It may imply for the Sri Lankan 
manufactures to re think since it may become stronger in the future with the world increasing concern on the green concept.

Also the present study profiling consumer segments based on their preference for branded apparels nonbranded apparels. Thus, it gives important implications for apparel manufacturers. Based the findings, consumers who prefer to buy ecofriendly branded apparels tend to have a unique lifestyle and shopping orientation. Interestingly, they are not necessarily from the highest income group, but they are big spenders on clothing and are willing to pay higher prices for brand, quality and image. However, it revealed that their attitude towards the environment lead them to prefer ecofriendly branded apparels.

The results of the study on influencing factors to the purchase intention would have been a great advantage for the apparel manufacturers and retailers. In view of the competitive landscape of the textile and apparel industry, it is vital for the manufacturers, retailers, marketers and other relevant parties to be more diligent in attracting and stay relevant to the needs and wants of the potential customers. Understanding what arouse customers' purchase intention in apparel market would be useful for them to accurately segment their target market, develop effective promotion strategies, and create loyalty among the customers.

Day by day the apparel industry is expanding and becoming competitive. Such studies on factors affecting purchase intention among consumers in the Sri Lankan context will encourage Sri Lankan manufacturers to reconsider consumers' intention when they compete in the open market

While the results of the study are beneficial for the existing manufacturers and merchants in apparel industry in particular similarly it will be for the new comers who attempted to enter into the apparel market.

For the future researchers in the field, it can be suggested to conduct more studies specially focusing the eco consciousness of consumers and its trending growth. This variable applied to not only to the branded apparel industry but also other manufacturing industries. It is better to keep in touch with the changes of eco friendliness mind set of Sri Lankan customers despite the nature of the industry.

Generalizability of the results of the study to entire industry in Sri Lanka can be considered as one of the main limitations of the study, as it was carried out in a particular province and results may not be considered as the perception of the country as a whole.

\section{REFERENCES}

Aditi Mishal, R. D. (2017). Dynamics of environmental consciousness and green purchase behaviour". International Journal of Climate Change Strategies \& Management, 9.

Aggrawal, A. (2010). Impact of Consumer Perception on Buying Behavior in Apparel Retail Sector, with special reference to Selected Indian Cities.

Audrey Azoulay, J.N. K. (2003). Do brand personalityscalesreally 
measurebrand personality? Journal of Brand Management.

Cham T.H., N. C. (n.d.). Factors Influencing Clothing Interest and Purchase Intention: A Study of Generation $\mathrm{Y}$ Consumers in Malaysia.

Chi, T. (2015). Factors influencing purchase intention towards environmentally friendly apparel: An empirical study of US consumers. International Journal of Fashion Design Technology and Education. Retrieved from https://www.researchgate.net/pub lication/269337096

Connell, K. Y. (2011). Exploring consumers' perceptions of ecoconscious apparel acquisition behaviors. Social Responsibility Journal, 7.

Duong, N. (2019). Brand personality and its impacts on consumers' purchase intentions. 81.

Erdil, T. S. (2015). Effects of Customer Brand Perceptions on Store Image and Purchase Intention: An Application in Apparel Clothing. Science Direct, 196-205.

Farhat, R., \& Khan, D. M. (2011). "Importance of Brand Personality To Customer Loyalty: A Conceptual Study ". 11 .

Gam, H. J. (2011). "Are fashionconscious consumers more likely to adopt eco-friendly clothing?". fashion marrketing \& management journal.
Gil, A. G., \& Hellgren, D. (n.d.). "Brand Personality: Impact on Brand Trust and Consumer Preferences".

Han Gia Vuong, M. T. (2018). "Factors Influencing Millennials' Purchase Intention towards Fast Fashion Products: A Case Study in Vietnam". International Journal of Social Science and Humanity, 8.

Kandiraju, G. (2014). investigating the influence of perceived characteristics of innovation on the relationship between knowledge, attitudes and purchase intention towards eco-conscious apparel.

Keller, K. 1., \& Richey, K. (2006). The importance of corporate brand personality traits to a successful 21 st century business. Journal of Brand Management, 14.

Kim, A. K.J.K. (2008). Indian consumers' purchase intention toward a United States versus local brand. Journal of Business Research.

Lim, D. A. (2008). The Influence of Brand Associations on Brand Preference and Purchase Intention. Journal of International Consumer Marketing.

Minh Ly, P. T., \& Loc, T. L. (2017). "The Relationship between Brand Experience, Brand Personality \& Customer Loyalty". International Journal of Business and Economics, 16, 109-126. 
Nam, C., Dong, H., \& Lee, A. Y. (2017). Factors influencing consumers' purchase intention of green sportswear.

Nejad, H. V. (2016). "Brand personality toward customer purchase intention: the intermediate role of electronic word-of-mouth and brand equity". Asian Academy of Management Journal, 21.

Nikhashemi, S., \& Valaei , N. (2017). Generation Y consumers' buying behaviour in fashion apparel industry. Journal of Fashion Marketing and Management, 21(4).

Ondogan, D. (2016). The Importance of Brand in Ready Made Garment Consumption. International Journal of Business Management and Economic Research, 7, 612618.
Saeed, R., Lodhi, N. R., Khan, K. A., \& NKhurshid, N. (2013). "Measuring Impact of Influencing Purchase Intention Towards Green Products: Sahiwal Clothing Industry Perspective". World Applied Sciences Journal.

Wang, C.L. (2001). Consumer decision-making styles on domestic and imported brand clothing.

Xia Tong, J. S. (2017). Brand personality and its impact on brand trust and brand commitment: an empirical study of luxury fashion brands". International Journal of Fashion Design, Technology \& Education. 